\title{
Para-Selective Borylation of Monosubstituted Benzenes Using a Transient Mediator
}

\author{
Jie $\mathrm{Wu}^{\dagger}$, Zengwei Wang ${ }^{\boldsymbol{P}}$, Xiao-Yue Chen ${ }^{\dagger}$, Yichen $\mathrm{Wu}^{\dagger}$, Daoming Wang ${ }^{\dagger}$, Qian Peng*, , and Peng \\ Wang ${ }^{*} \dagger,+$
}

'State Key Laboratory of Organometallic Chemistry, Center for Excellence in Molecular Synthesis, Shanghai Institute of Organic Chemistry, CAS 345 Lingling Road, Shanghai 200032, China

${ }^{\ddagger}$ CAS Key Laboratory of Energy Regulation Materials, Shanghai Institute of Organic Chemistry, CAS 345 Lingling Road, Shanghai 200032, China

"State Key Laboratory of Elemento-Organic Chemistry, College of Chemistry, Nankai University, Tianjin 300071, China

\section{Supporting Information Placeholder}

\begin{abstract}
Herein, we conceptualized a transient mediator approach that has the capability of para-selective $\mathrm{C}-\mathrm{H}$ functionalization of monosubstituted aromatics. This approach is enabled by in situ generation of a versatile sulfonium salt via highly electrophilic phenoxathiine or thianthrene dication intermediate which can be readily generated from its sulfoxide with trifluoromethanesulfonic anhydride. Preliminary mechanistic study implied that the remarkable para selectivity might be related to the incredible electrophilicity of thianthrene dication intermediate. The versatility of this approach was demonstrated via para-borylation of various monosubstituted simple aromatics combining the sulfonium salt formation with further photocatalyzed transformation.
\end{abstract}

Tremendous efforts have been made in the field of precise control the site selectivity in $\mathrm{C}-\mathrm{H}$ functionalization of aromatics during the past two decades. ${ }^{1-2}$ However, achieving para-selectivity in direct $\mathrm{C}-\mathrm{H}$ functionalization reactions remains a significant challenge, especially when the targeted arene owns multiple reactive sites with subtle steric and electronic discrepancy. Typically, para-selectivity control often dominated by steric and electronic factors of substrates, and high selectivity was observed mainly for electron-rich arenes, which have been represented in electrophilic aromatic substitution reaction of aromatics. ${ }^{3}$ Recently, major progress to face this challenging para-C-H functionalization has been achieved through electronic recognition, ${ }^{4}$ steric control, ${ }^{5}$ template assistance, ${ }^{6}$ and radical involved processes ${ }^{7}$ (Scheme 1A). Despite undisputable advances, those methods are still lack of generality with insufficient regioselectivity, either requiring large excess of arenes or working with the assistance of directing group (template), and normally resulting in a mixture of para-substituted product with other isomers. The development of general and efficient approaches to achieve para-C-H functionalization without directing group assistance remains a significant task. Herein, we conceptualized a transient mediator approach that enables para-selective functionalization of monosubstituted benzene derivatives (Scheme 1B). We envisioned that a mediator could be selectively introduced to the para position of the substituents via a highly electrophilic cation or radical cation intermediate
Scheme 1. Background and Synopsis for para-C-H Functionalization of Monosubstituted Arenes

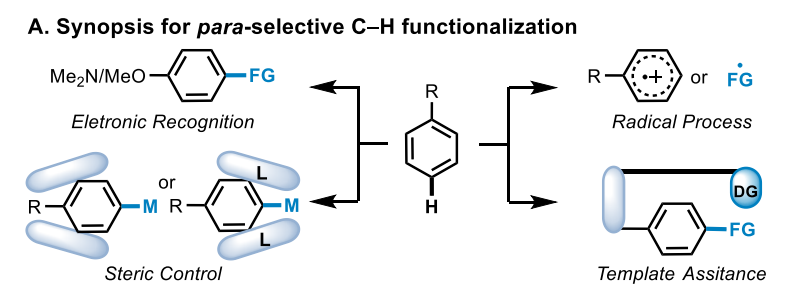

B. Transient mediator approach for para-selective functionalization

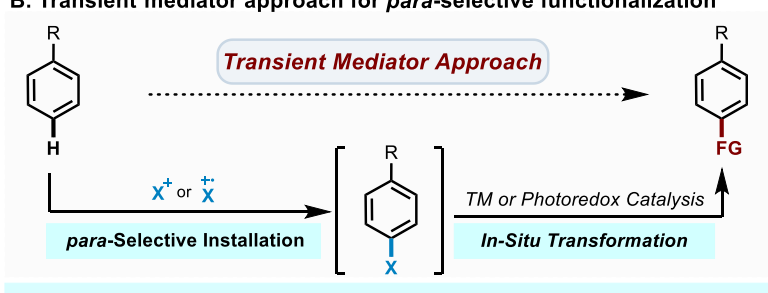

C. This Work: Para-selective borylation of monosubstituted arenes

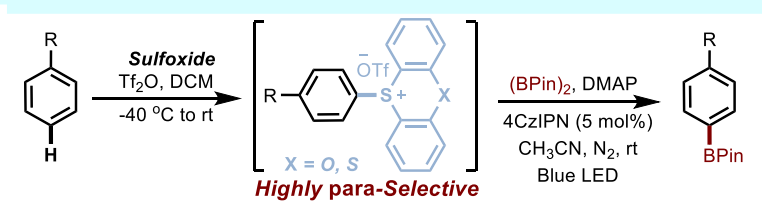

with electron or steric recognition. This resulted species could be readily converted to other functionalities with high efficiency providing the para-decorated aromatics. By carefully selecting the transient mediator and conditions, para-functionalization of monosubstituted benzene could be realized in a single synthetic operation. In this case, highly electrophilic phenoxathiine or thianthrene radical cation intermediate, ${ }^{8}$ in situ initiated by its sulfoxide with trifluoromethanesulfonic anhydride, was capable of generating the corresponding sulfonium salt with a high para-selectivity. Para-borylation of monosubsituted benzene was realized by combining the sulfonium salt formation with further photocatalyzed borylation using phenoxathiine or thianthrene as the transient mediator. 
We started our investigation by searching a suitable transient mediator, which has the capability of being installed at the paraposition of the monosubstituted aromatics with high selectivity, and being readily converted to other functional groups. Be aware of the remarkable activity of sulfide ditriflate, a highly active intermediate formed in situ by treating sulfide oxide with $\mathrm{Tf}_{2} \mathrm{O}$, ${ }^{9}$ we hypothesized that the electrophilic sulfate ditriflate reagents might be a potential handle for addressing this challenging problem by adjusting the steric effects. In situ generated dimethyl sulfide ditriflate (DMSD) reacted with toluene providing the corresponding sulfonium salts in $99 \%$ yield with an insufficient selectivity $(p / o=1.5 / 1.0)$. The selectivity was slightly improved with the increase of steric hindrances (2b-e). Diisopropyl sulfoxide (2f) gave a remarkable para/ortho ratio of $>20 / 1.0$, whereas the efficiency of sulfonium salt formation is unsatisfying and cannot be further improved probably due to bulky isopropyl substituent. It is noteworthy that methyl phenyl sulfoxide (2h) maintained the high efficiency and high selectivity simultaneously, giving 10.0/1.0 selectivity and 95\% yield. Encouraged by this result, we decided to focus on evaluation of aryl sulfoxides (2i-n). Despite more steric hindrance sulfoxide $\mathbf{2 i}$ led to lower reactivity, diphenyl sulfoxide $\mathbf{2} \mathbf{j}$ provided its sulfonium salt in quantitative yield with similar selectivity. Compared to diphenyl sulfoxide, less steric hindrance dibenzothiophene sulfoxide (2k) and thioxanthone sulfoxide (2l) resulted in lower selectivities. Gratifyingly, phenoxathiine sulfoxide (2m) and thianthrene sulfoxide (2n) significantly improved the selectivity to $>76 / 1$ (para/ortho) with high efficiency.

Scheme 2. Evaluation of Sulfoxides. ${ }^{a, b}$

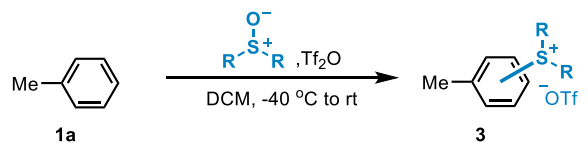

\begin{tabular}{|c|c|c|c|c|}
\hline $\mathrm{Me}$ & $\begin{array}{l}\mathrm{O}^{-} \\
1^{+} \\
S^{+} \\
\mathrm{Et}\end{array}$ & $10 n_{\mathrm{E}}$ & $\begin{array}{c}\mathrm{O}^{-} \\
{ }^{1} \mathrm{Pr}^{-} \\
\mathrm{S}^{+} \mathrm{Me}\end{array}$ & $\mathrm{Bn}^{-\mathrm{S}^{-}} \stackrel{\mathrm{O}^{-}}{+} \mathrm{Me}$ \\
\hline $\begin{array}{c}2 a, 99 \% \\
p / o=1.5 / 1.0\end{array}$ & $\begin{array}{c}\mathbf{2 b}, 80 \% \\
p / o=2.1 / 1.0\end{array}$ & $\begin{array}{c}2 c, 79 \% \\
p / o=2.1 / 1.0\end{array}$ & $\begin{array}{c}\mathbf{2 d}, 39 \% \\
p / o=2.4 / 1.0\end{array}$ & $\begin{array}{c}2 e, 42 \% \\
p / o=2.7 / 1.0\end{array}$ \\
\hline
\end{tabular}

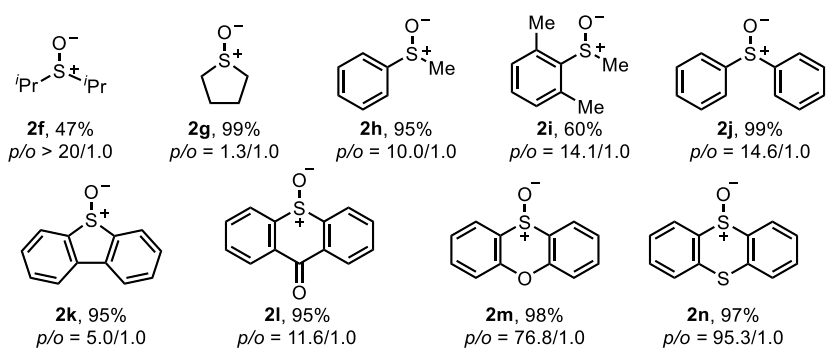

${ }^{a}$ Conditions: toluene $(0.5 \mathrm{mmol})$, sulfoxide $(0.6 \mathrm{mmol}), \mathrm{Tf}_{2} \mathrm{O}(0.6$ $\mathrm{mmol}), \mathrm{DCM}(0.5 \mathrm{~mL}), \mathrm{N}_{2} ;-40{ }^{\circ} \mathrm{C}$ for $30 \mathrm{~min}$, then rt for $1 \mathrm{~h} .{ }^{b} \mathrm{The}$ yield was determined by ${ }^{1} \mathrm{H}$ NMR using $\mathrm{CH}_{2} \mathrm{Br}_{2}$ as the internal standard. The selectivity was determined by the ${ }^{1} \mathrm{H}$ NMR.

To shed light on the causation for remarkable para selectivity using phenoxathiine and thianthrene derived sulfoxide, detailed mechanistic studies were carried out. Although the sulfoxide screening confirmed that the regioselectivity can be partially controlled by the steric effects, the EPR experiment of the reaction system with various in situ generated sulfide ditriflates indicated that the striking para-selecitivity might also be related to the formation of phenoxathiine ${ }^{10 \mathrm{a}}$ and thianthrene radical cation intermediates. ${ }^{10 b-f, 11}$ In comparison, thioxanthone sulfoxide
Figure 1. Mechanistic Study

A. EPR response for various sulfate ditriflates

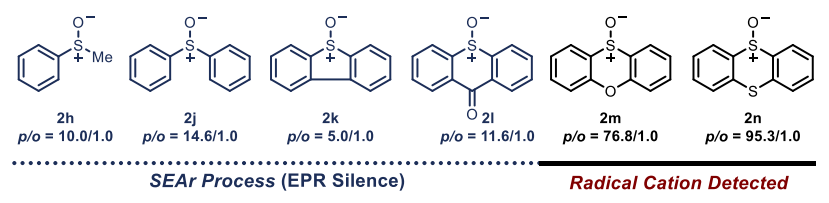

B. Computational study

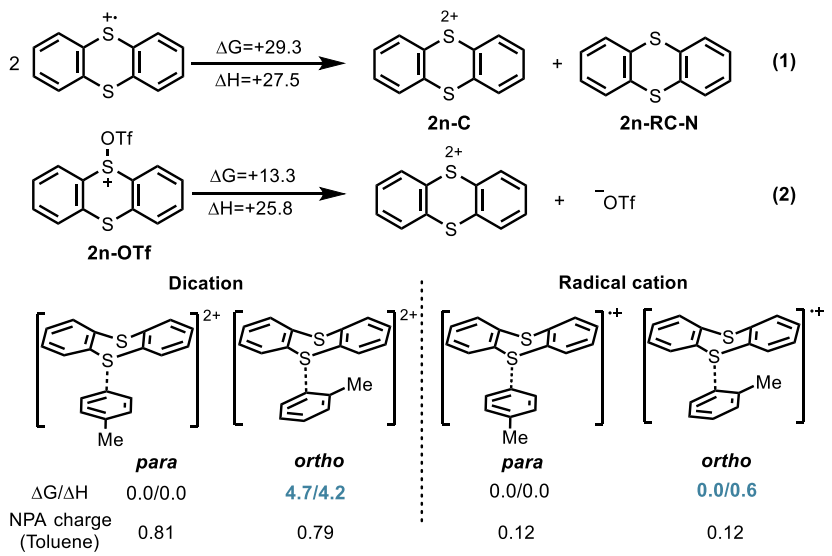

C. Proposed mechanism for para-selective sulfonium salts formation

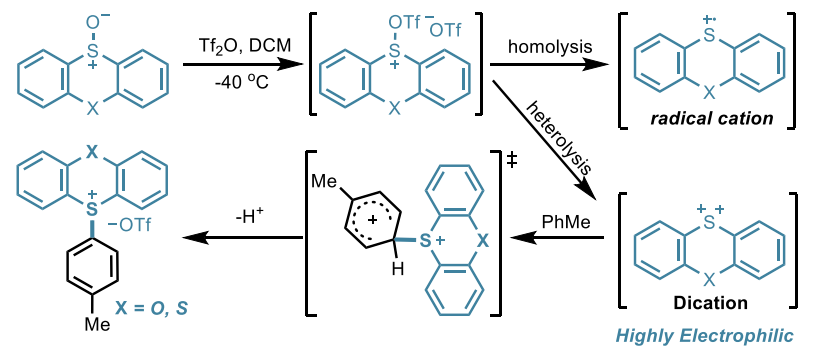

(21) with similar scaffold without EPR response resulted in a lower para selectivity (Figure 1A). However, the reaction didn't proceed at low concentration of sulfoxide and $\mathrm{Tf}_{2} \mathrm{O}$, despite the radical cation intermediate existed which confirmed by the EPR experiment. We hence doubted whether the radical cation intermediate is real reactive species for sulfonium salts formation, and were intrigued by the origin of the outstanding regioselectivity. To further understand this process, preliminary computational studies were performed at SMD-M062x/def2TZVP level of theory, and three possible intermediates, radical cation, radical cation dimer and sulfide dication, were systematically investigated. The intermediates of $\mathrm{C}-\mathrm{S}$ formation with toluene and thianthrene radical cation didn't show apparently energy difference $(<0.6 \mathrm{kcal} / \mathrm{mol})$ indicating the poor selectivity of para/ortho position by the calculated energy scanning of forming C-S distance (see Figure S8). Based on Dunsch's study (ref $10 \mathrm{~g}$ ), a dimer intermediate could be formed via a reversible dimerization of thianthrene radical cation, however, the dimer can't lead to stable adducts for the reasonable para/ortho selectivity in the electrophilic substitution of toluene through calculations (see Figure S9) We next turned our attention to the plausible thianthrene dication intermediate, and found the sulfide dication intermediate is facile from heterolysis of sulfide ditriflate 2n-OTf with slightly endothermic rather than disproportionation from thianthrene radical cation. The large free energy difference $(>4.0 \mathrm{kcal} / \mathrm{mol})$ between para- and ortho- intermediates imply that the sulfide dication would be the possible 
Scheme 3. Scope of Monosubstituted Arenes. ${ }^{a, b}$

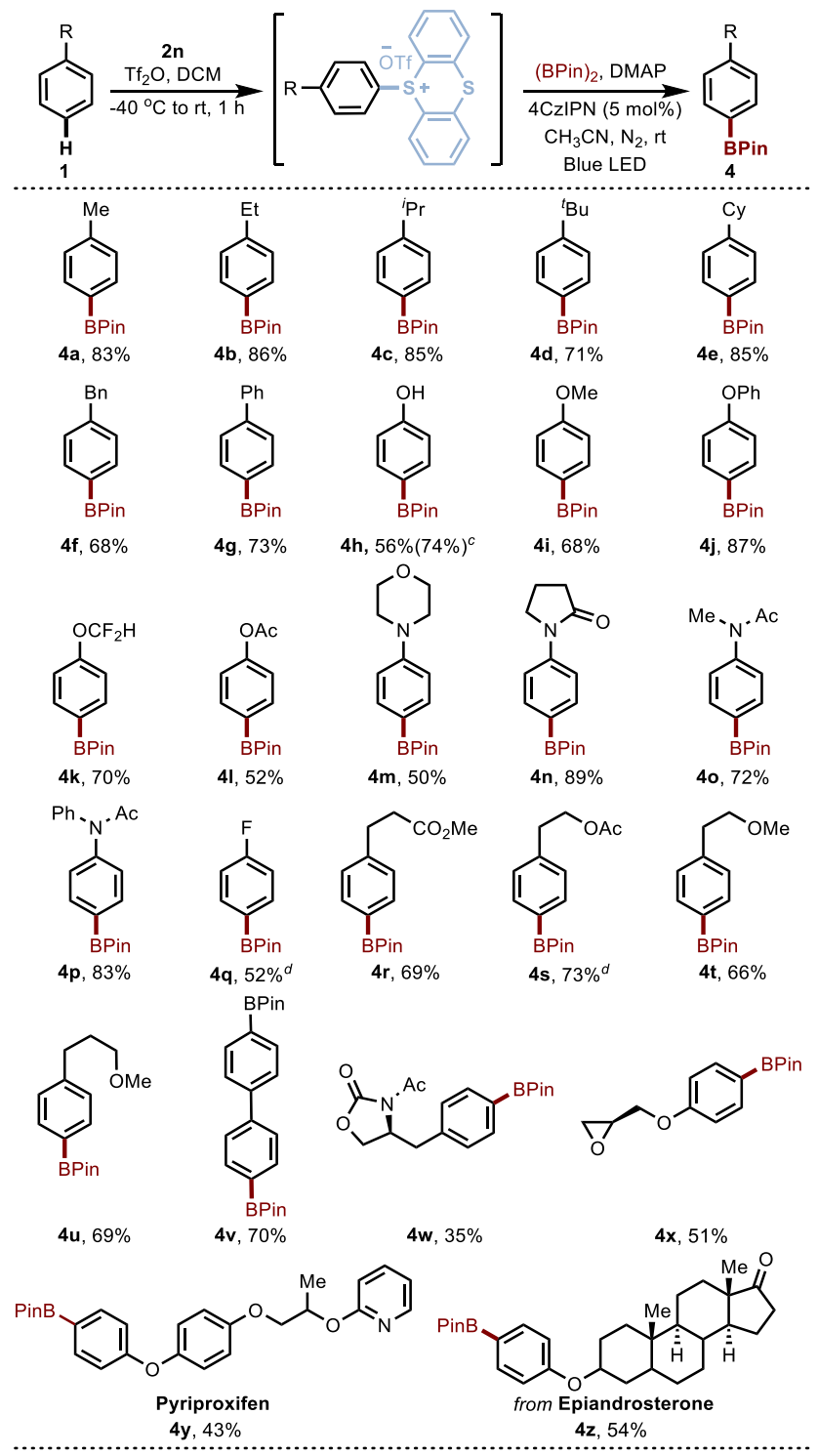

Other inefficient substrates (NMR yield)

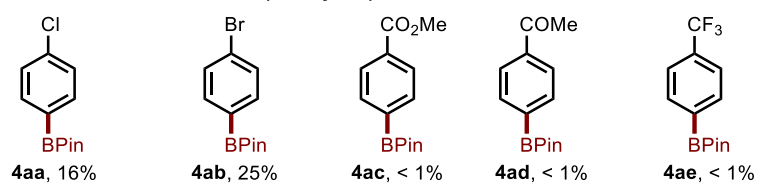

${ }^{a}$ Reaction conditions: 1$) \mathbf{1}$ ( $\left.0.2 \mathrm{mmol}\right), 2 \mathrm{n}$ (1.2 equiv), $\mathrm{Tf}_{2} \mathrm{O}$ (1.2 equiv), $\mathrm{DCM}(1.0 \mathrm{~mL}),-40^{\circ} \mathrm{C}$ to rt, $\left.1 \mathrm{~h} ; 2\right)$ DMAP $(2.0+2.0$ equiv $)$, 4-CzIPN (5 mol \%), (BPin)2 (4.0 equiv), Blue LED, 8 h. ${ }^{b}$ Isolated yield; for all substrates, high para selectivities were obtained (para/others $>50 / 1)$. ${ }^{c}$ TIPS-protected phenol was used. ${ }^{d}$ Reaction conditions: $\mathbf{2 n}$ ( 2.4 equiv), $\mathrm{Tf}_{2} \mathrm{O}$ ( 2 equiv) and DMAP $(3+2$ equiv.) were used rather than the standard conditions.

active species responsible for the high regioselectivity. And the dispersedly positive NPA charge (see Figure S11) on both thianthrene and toluene lead the exo-conformation in the favorable para-intermediate to minimize the electrostatic repulsions, which can rationalize the experimental observation of high $p / o$ ration. Based on the DFT study, we therefore postulated that the para-selective sulfonium formation proceeded via electronic substitution with the highly electrophilic sulfide dication intermediate, followed by deprotonation to form sulfonium salts (Figure 1C). Besides, the less efficiency with electron-deficient substrates, like $\mathrm{PhCF}_{3}, \mathrm{PhCO}_{2} \mathrm{Me}$, also supported this reaction proceeded via cation intermediates. ${ }^{11 \mathrm{a}}$

Given the versatility of aryl boronic acid in organic synthesis, ${ }^{12}$ we are curious if we can achieve the para-borylation of monosubstituted benzenes by in situ converting the resulted sulfonium salt ${ }^{13}$ in a single synthetic operation. Several elegant examples towards the challenging para- $\mathrm{C}-\mathrm{H}$ borylation of arenes have been witnessed in the last decade. For example, Itami and coworkers $^{5 a}$ have reported an Ir-catalyzed para-C-H borylation by altering the steric hindrance on ligands, moderate to poor para selectivity was obtained using less congested monosubstituted arenes, such as cumene (para:others $=58: 42$ ) and ethylbenzene (para:others $=32: 68$ ). Recently, Nakao Group ${ }^{5 \mathrm{~d}-\mathrm{f}}$ and Chattopadhyay group ${ }^{6 c}$ has achieved the Ir-catalyzed paraselective borylation of aromatic esters and amides in high selectivity by adopting the rational designed bimetallic or noncovalent interaction strategy. However, those strategies cannot be extended to undirected aromatics without polar functional group assistance. After scrupulously evaluated the reaction parameters for para-borylation, we found the para-borylated toluene can be obtained in $83 \%$ yield using DMAP as base and activator, $4 \mathrm{CzIPN}$ as photocatalyst in $\mathrm{CH}_{3} \mathrm{CN}$ (For detailed screening, see Supporting Information). With the optimized conditions in hand, the generality of this protocol was examined. As summarized in Scheme 3, alkylated benzene derivatives provided desired borylated products in high yields (4a-e), while diphenylmethane gave moderate yield (4f, $68 \%$ yield). Biphenyl also produced the corresponding boronic acid pinacol ester in 73\% yield (4g). Electron rich phenol (1h-l) and aniline (1 m-p) derivatives are also suitable substrates for this protocol, in which the tolerance with difloromethoxybenzene, $\mathrm{N}$-phenylmorpholine, 1-phenyl-2-pyrrolidinone are noteworthy. TIPSprotected phenol (1h) provided the unmasked para borylated phenol in $74 \%$ yield, whereas phenol also can be used in the reaction with slightly lower yield. Electron-deficient fluorobenzene (1q) was compatible with this procedure along with high para selectivity. Derivatives of hydrocinnamic acid (1r), 2-phenylethanol (1s 1t), phenylpropanol (1u), borylated biphenyl (1v), $L$-phenylalaninol (1w), and $(S)$-2-oxiranylanisole (1x) underwent this protocol yielding the desired products in moderate to high yields. Some complex scaffolds $(\mathbf{1 y}, \mathbf{1 z})$ were also compatible, demonstrating this protocol is versatile for late-stage functionalization of drug molecules. Moreover, the electron deficient substrates provided low activities (1aa-ae) probably due to the electrophilic nature of dication intermediate in the sulfonium salts formation step.

The para-borylated products can be readily transformed to various para-decorated arenes efficiently as summarized in Scheme 4. Using $4 \mathbf{n}$ as model scaffold, the boronic acid pinacol ester can be smoothly converted to alkenyl, aryl, iodide, methoxyl, and aminyl in high efficiency. This protocol opens a new avenue for synthesis of 1,4-disubstituted arenes, a scaffold frequently found in biologically active compounds. 
Scheme 4. Transformation of Aryl Boron

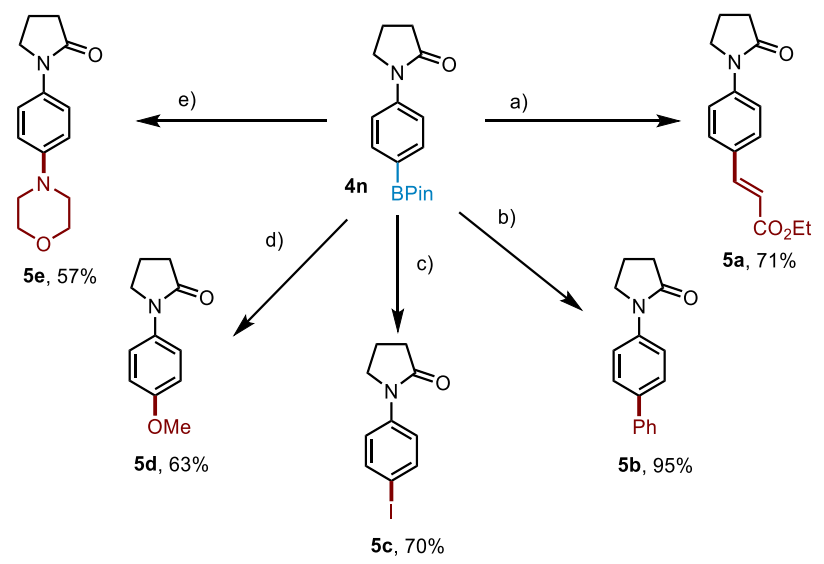

Conditions: a) $\mathrm{CH}=\mathrm{CHCO}_{2} \mathrm{Et}, \mathrm{Pd}(\mathrm{OAc})_{2}(10 \mathrm{~mol} \%), \mathrm{Na}_{2} \mathrm{CO}_{3}(2.0$ equiv), DMF, $50{ }^{\circ} \mathrm{C}, \mathrm{O}_{2}, 3 \mathrm{~h}$; b) $\mathrm{PhBr}$ (1.0 equiv), $\mathrm{Pd}(\mathrm{dppf}) \mathrm{Cl}_{2}(5$ mol \%), $\mathrm{K}_{3} \mathrm{PO}_{4}$ (3.0 equiv), $\mathrm{H}_{2} \mathrm{O}$ (5.0 equiv), THF, $70{ }^{\circ} \mathrm{C}, 3 \mathrm{~h} ; \mathrm{c}$ ) $\mathrm{KI}$ (1.5 equiv), $\mathrm{CuI}(10 \mathrm{~mol} \%), 1,10$-phenanthroline (20 mol \%), $\mathrm{MeOH} / \mathrm{H}_{2} \mathrm{O}$ (4:1), $\left.80{ }^{\circ} \mathrm{C}, 20 \mathrm{~h} ; \mathrm{d}\right) \mathrm{MeOH}, \mathrm{Cu}(\mathrm{OAc})_{2}$ (1.0 equiv), DMAP (2.0 equiv), $4 \AA$ MS, rt, air, $24 \mathrm{~h}$; e) morpholine (2.0 equiv), $\mathrm{Cu}(\mathrm{OAc})_{2}$ (1.0 equiv), $\mathrm{Et}_{3} \mathrm{~N}$ (2.0 equiv), $4 \AA \mathrm{MS}, \mathrm{CH}_{3} \mathrm{CN}, 80^{\circ} \mathrm{C}$, air, $24 \mathrm{~h}$.

In summary, para-borylation of monosubstituted benzenes has been demonstrated using phenoxathiine or thianthrene as the transient mediator. Preliminary mechanistic study indicated that the key to the remarkable para-selectivity might be the use of highly electrophilic phenoxathiine or thianthrene dication species. Detailed mechanistic study and the application of this transient mediator approach for site-selective functionalization are ongoing projects in our laboratory.

\section{ASSOCIATED CONTENT}

Experimental procedures, complete characterization data, copies of ${ }^{1} \mathrm{H}$ and ${ }^{13} \mathrm{C}$ NMR spectra. The Supporting Information is available free of charge via the Internet at http://pubs.acs.org.

\section{AUTHOR INFORMATION}

\section{Corresponding Author}

Email: qpeng@nankai.edu.cn; pengwang@sioc.ac.cn

\section{ACKNOWLEDGMENT}

We gratefully acknowledge Shanghai Institute of Organic Chemistry, State Key Laboratory of Organometallic Chemistry, the National Natural Science Foundation of China (Grants 21890722, 21702109, and 11811530637), the Natural Science Foundation of Tianjin City (18JCYBJC21400), and the Fundamental Research Funds for the Central Universities (No. 63191515, 63196021, 63191523 ) for financial support.

\section{REFERENCES}

(1) For selected reviews on $\mathrm{C}-\mathrm{H}$ functionalization, see: (a) Alberico, D.; Scott, M. E.; Lautens, M. Aryl-Aryl Bond Formation by Transition-Metal-Catalyzed Direct Arylation. Chem. Rev. 2007, 107, 174 238; (b) Chen, X.; Engle, K. M.; Wang, D.-H.; Yu, J.-Q. Palladium(II)-
Catalyzed C-H Activation/C-C Cross-Coupling Reactions: Versatility and Practicality. Angew. Chem. Int. Ed. 2009, 48, 5094-5115; (c) Daugulis, O.; Do, H.-Q.; Shabashov, D. Palladium- and Copper-Catalyzed Arylation of Carbon-Hydrogen Bonds. Acc. Chem. Res. 2009, 42, 1074-1086; (d) Mkhalid, I. A. I.; Barnard, J. H.; Marder, T. B.; Murphy, J. M.; Hartwig, J. F. C-H Activation for the Construction of $\mathrm{C}-\mathrm{B}$ Bonds. Chem. Rev. 2010, 110, 890-931; (e) Lyons, T. W.; Sanford, M. S. Palladium-Catalyzed Ligand-Directed $\mathrm{C}-\mathrm{H}$ Functionalization Reactions. Chem. Rev. 2010, 110, 1147-1169; (f) Colby, D.A.; Bergman, R. G.; Ellman, J. A. Rhodium-Catalyzed $\mathrm{C}-\mathrm{C}$ Bond Formation via Heteroatom-Directed C-H Bond Activation. Chem. Rev., 2010, 110, 624655; (g) Yeung, C. S.; Dong, V. M. Catalytic Dehydrogenative CrossCoupling: Forming Carbon-Carbon Bonds by Oxidizing Two Carbon-Hydrogen Bonds. Chem. Rev. 2011, 111, 1215-1292; (h) Arockiam, P. B.; Bruneau, C.; Dixneuf, P. H. Ruthenium(II)-Catalyzed C-H Bond Activation and Functionalization. Chem. Rev. 2012, 112, 58795918; (i) Liu, C.; Yuan, J.; Gao, M.; Tang, S.; Li, W.; Shi, R.; Lei, A. Oxidative Coupling between Two Hydrocarbons: An Update of Recent C-H Functionalizations. Chem. Rev. 2015, 115, 12138-12204; (j) He, G.; Wang, B.; Nack, W. A.; Chen, G. Syntheses and Transformations of $\alpha$-Amino Acids via Palladium-Catalyzed Auxiliary-Directed $\mathrm{sp}^{3} \mathrm{C}-$ H Functionalization. Acc. Chem. Res. 2016, 49, 635-645; (k) Gensch, T.; Hopkinson, M. N.; Glorius, F.; Wencel-Delord, J. Mild Metal-Catalyzed C-H Activation: Examples and Concepts. Chem. Soc. Rev. 2016, 45, 2900-2936; (1) Yang, Y.; Lan, J.; You, J. Oxidative C-H/C-H Coupling Reactions between Two (Hetero)arenes. Chem. Rev. 2017, 117, $8787-8863$.

(2) For reviews on remote $\mathrm{C}-\mathrm{H}$ functionalization, see: (a) Schranck, J.; Tlili, A.; Beller, M. Functionalization of Remote C-H Bonds: Expanding the Frontier. Angew. Chem. Int. Ed. 2014, 53, 9426-9428; (b) Yang, J. Transition Metal Catalyzed meta-C-H Functionalization of Aromatic Compounds. Org. Biomol. Chem. 2015, 13, 1930-1941; (c) Li, J.; Ackermann, L. Following Directions. Nat. Chem. 2015, 7, 686687; (d) Li, J.; De Sarkar, S.; Ackermann, L. meta- and para-Selective $\mathrm{C}-\mathrm{H}$ Functionalization by C-H Activation. Top. Organomet. Chem. 2016, 55, 217-257; (e) Ping, L.; Chung, D. S.; Bouffard, J.; Lee, S.-g. Transition Metal-Catalyzed Site- and Regio-Divergent $\mathrm{C}-\mathrm{H}$ Bond Functionalization. Chem. Soc. Rev. 2017, 46, 4299-4328; (f) Leitch, J. A.; Frost, C. G. Ruthenium-Catalysed $\sigma$-Activation for Remote metaSelective C-H Functionalization. Chem. Soc. Rev. 2017, 46, 71457153; (g) Khan, F. F.; Sinha, S. K.; Lahiri, G. K.; Maiti, D. RutheniumMediated Distal C-H Activation. Chem. Asian J. 2018, 13, 2243-2256; (h) Dey, A.; Sinha, S. K.; Achar, T. K.; Maiti, D. Angew. Chem. Int. Ed. 2018, Accessing Remote meta- and para-C(sp2)-H Bonds with Covalently Attached Directing Groups. DOI: 10.1002/anie.201812116; (i) Haldar, C.; Hoque, M. E.; Bisht, R.; Chattopadhyay, B. Concept of Ir-catalyzed $\mathrm{C}-\mathrm{H}$ bond activation/borylation by noncovalent interaction. Tetrahedron Lett. 2018, 59, 1269-1277.

(3) (a) Taylor, R. Electrophilic Aromatic Substitution; Wiley: New York, 1990; (b) P. B. de la Mare in Electrophilic Halogenation; Elmore, D. T.; Leadbetter, A.; Schofield, K. Eds.: Cambridge University Press: Cambridge, 1976; Chapter 5; (c) Olah, G. A. Acc. Chem. Res. Aromatic Substitution. XXVIII. Mechanism of Electrophilic Aromatic Substitutions. 1971, 4, 240-248.

(4) (a) Ciana, C.-L.; Phipps, R. J.; Brandt, J. R.; Meyer, F.-M.; Gaunt, M. J. A Highly para-Selective Copper(II)-Catalyzed Direct Arylation of Aniline and Phenol Derivatives. Angew. Chem., Int. Ed. 2011, 50, 458-462; (b) Wang, X.; Leow, D.; Yu, J.-Q. Pd(II)-Catalyzed paraSelective C-H Arylation of Monosubstituted Arenes. J. Am. Chem. Soc 2011, 133, 13864-13867; (c) Ball, L. T.; Lloyd-Jones, G. C.; Russell, C. A. Gold-Catalyzed Direct Arylation. Science, 2012, 337, 1644-1648; (d) Wagner, A. M.; Hickman, A. J.; Sanford, M. S. Platinum-Catalyzed C-H Arylation of Simple Arenes. J. Am. Chem. Soc. 2013, 135, 15710 15713; (e) Hu, X.; Martin, D.; Melaimi, M.; Bertrand, G. Gold-Catalyzed Hydroarylation of Alkenes with Dialkylanilines. J. Am. Chem. Soc. 2014, 136, 13594-13597; (f) Yu, Z.; Ma, B.; Chen, M.; Wu, H.H.; Liu, L.; Zhang, J. Highly Site-Selective Direct C-H Bond Func- 
tionalization of Phenols with $\alpha$-Aryl- $\alpha$-diazoacetates and Diazooxindoles via Gold Catalysis. J. Am. Chem. Soc. 2014, 136, 6904-6907; (g) Yadagiri, D.; Anbarasan, P. Rhodium Catalyzed Direct Arylation of $\alpha$ Diazoimines. Org. Lett. 2014, 16, 2510-2513; (h) Berzina, B.; Sokolovs, I.; Suna, E. Copper-Catalyzed para-Selective C-H Amination of Electron-Rich Arenes. ACS Catal. 2015, 5, 7008-7014; (i) Paudyal, M. P.; Adebesin, A. M.; Burt, S. R.; Ess, D. H.; Ma, Z.; Kürti, L.; Falck, J. R. Dirhodium-catalyzed C-H Arene Amination using Hydroxylamines. Science 2016, 353, 1144-1147; (j) Ma, Y.; Wang, B.; Zhang, L.; Hou, Z. Boron-Catalyzed Aromatic C-H Bond Silylation with Hydrosilanes. J. Am. Chem. Soc. 2016, 138, 3663-3666; (k) Ma, B.; Chu, Z.; Huang, B.; Liu, Z.; Liu, L.; Zhang, J. Highly para-Selective $\mathrm{C}-\mathrm{H}$ Alkylation of Benzene Derivatives with 2,2,2-Trifluoroethyl $\alpha$-Aryl- $\alpha$-Diazoesters. Angew. Chem. Int. Ed. 2017, 56, 2749-2753. For electronic recognition using high valent Pd catalyst: (1) Luan, Y.X.; Zhang, T.; Yao, W.-W.; Lu, K.; Kong, L.-Y.; Lin, Y.-T.; Ye, M. Amide-Ligand-Controlled Highly para-Selective Arylation of Monosubstituted Simple Arenes with Arylboronic Acids. J. Am. Chem. Soc. 2017, 139, 1786-1789.

(5) (a) Cheng, C.; Hartwig, J. F. Rhodium-Catalyzed Intermolecular $\mathrm{C}-\mathrm{H}$ Silylation of Arenes with High Steric Regiocontrol. Science 2014, 343, 853-857; (b) Saito, Y.; Segawa, Y.; Itami, K. para-C-H Borylation of Benzene Derivatives by a Bulky Iridium Catalyst. J. Am. Chem. Soc. 2015, 137, 5193-5198; (c) Haines, B. E.; Saito, Y.; Segawa, Y.; Itami, K.; Musaev, D. G. Flexible Reaction Pocket on Bulky Diphosphine-Ir Complex Controls Regioselectivity in para-Selective $\mathrm{C}-\mathrm{H}$ Borylation of Arenes. ACS Cat. 2016, 6, 7536-7546; (d) Okumura, S.; Tang, S.; Saito, T.; Semba, K.; Sakaki, S.; Nakao, Y. para-Selective Alkylation of Benzamides and Aromatic Ketones by Cooperative Nickel/Aluminum Catalysis. J. Am. Chem. Soc. 2016, 138, 14699 14704; (e) Okumura, S.; Nakao, Y. para-Selective Alkylation of Sulfonylarenes by Cooperative Nickel/Aluminum Catalysis. Org. Lett. 2017, 19, 584-587; (f) Yang, L.; Semba, K.; Nakao, Y. para-Selective $\mathrm{C}-\mathrm{H}$ Borylation of (Hetero)Arenes by Cooperative Iridium/Aluminum Catalysis. Angew. Chem. Int. Ed. 2017, 56, 4853-4857; (g) Tian, C.; Yao, X.; Ji, W.; Wang, Q.; An, G.; Li, G. A para-C-H Functionalization of Aniline Derivatives via in situ Generated Bulky Hypervalent Iodinium Reagents. Eur. J. Org. Chem. 2018, 5972-5979.

(6) (a) Bag, S.; Patra, T.; Modak, A.; Deb, A.; Maity, S.; Dutta, U.; Dey, A.; Kancherla, R.; Maji, A.; Hazra, A.; Bera, M.; Maiti, D. Remote para-C-H Functionalization of Arenes by a D-Shaped Biphenyl Template-Based Assembly. J. Am. Chem. Soc. 2015, 137, 11888 11891; (b) Patra, T.; Bag, S.; Kancherla, R.; Mondal, A.; Dey, A.; Pimparkar, S.; Agasti, S.; Modak, A.; Maiti, D. Palladium-Catalyzed Directed para $\mathrm{C}-\mathrm{H}$ Functionalization of Phenols. Angew. Chem. Int. Ed. 2016, 55, 7751-7755; (c) Hoque, M. E.; Bisht, R.; Haldar, Chabush.; Chattopadhyay, B. Noncovalent Interactions in Ir-Catalyzed C-H Activation: L-Shaped Ligand for para-Selective Borylation of Aromatic Esters. J. Am. Chem. Soc. 2017, 139, 7745-7748; (d) Maji. A; Guin, S.; Feng, S.; Dahiya, A.; Singh, V. K.; Liu, P.; Maiti, D. Experimental and Computational Exploration of para-Selective Silylation with a Hydrogen-Bonded Template. Angew. Chem. Int. Ed. 2017, 56, 14903-14907; (e) Maji, A.; Dahiya, A.; Lu, G.; Bhattacharya, T.; Brochetta, M.; Liu, P.; Zanoni, G.; Maiti, D. H-Bonded Template Assisted Para Selective Carboalkylation Using Soft Electrophilic Vinyl Ether. Nat. Commun. 2018, DOI: 10.1038/s41467-018-06018-2; (f) Li, M.; Shang, M.; Xu, H.; Wang, X.; Dai, H.-X.; Yu, J.-Q. Remote para-C-H Acetoxylation of Electron-Deficient Arenes. Org. Lett. 2019, 21, 540-544; (g) Dutta, U.; Maiti, S.; Pimparkar, S.; Maiti, S.; Gahan, L. R.; Krenske, E. H.; Lupton, D. W.; Maiti, D. Rhodium Catalyzed Template-Assisted Distal para-C-H Olefination Chem. Sci. 2019, DOI: 10.1039/C9SC01824G.

(7) (a) Guo, X.; Li, C.-J. Ruthenium-Catalyzed para-Selective Oxidative Cross-Coupling of Arenes and Cycloalkanes. Org. Lett. 2011, 13, 4977-4979; (b) Romero, N. A.; Margery, K. A.; Tay, N. E.; Nicewicz, D. A. Site-Selective Arene C-H Amination via Photoredox Catalysis. Science 2015, 349, 1326-1330; (c) Boursalian, G. B.; Ham, W. S.; Mazzotti, A. R.; Ritter, T. Charge-Transfer-Directed Radical Substitution Enables para-Selective C-H Functionalization. Nat. Chem.
2016, 8, 810-815; (d) Leitch, J. A.; McMullin, C. L.; Paterson, A. J.; Mahon, M. F.; Bhonoah, Y.; Frost, C. G. Ruthenium-Catalyzed paraSelective $\mathrm{C}-\mathrm{H}$ Alkylation of Aniline Derivatives. Angew. Chem. Int. Ed. 2017, 56, 15131-15135; (e) Yuan, C.; Zhu, L.; Zeng, R.; Lan, Y.; Zhao, Y. Ruthenium(II)-Catalyzed C-H Difluoromethylation of Ketoximes: Tuning the Regioselectivity from the meta to the para Position. Angew. Chem. Int. Ed. 2018, 57, 1277-1281; (f) Yuan, C.; Zhu, L.; Chen, C.; Chen, X.; Yang, Y.; Lan, Y.; Zhao, Y. Ruthenium(II)Enabled para-Selective C-H Difluoromethylation of Anilides and Their Derivatives. Nat. Commun. 2018, 9, 1189; (g) Serpier, F.; Pan, F.; Ham, W. S.; Jacq, J.; Genicot, C.; Ritter, T. Selective Methylation of Arenes: A Radical C-H Functionalization/Cross-Coupling Sequence. Angew. Chem. Int. Ed. 2018, 57, 10697-10701. (h) Fosu, S. C.; Hambira, C. M.; Chen, A. D.; Fuchs, J. R.; Nagib, D. A. Selective Methylation of Arenes: A Radical C-H Functionalization/Cross-Coupling Sequence. Chem. 2019, 5, 417-428; (i) Mao, Y.-J.; Wang, B.-X.; Wu, Q.-Z.; Zhou, K.; Lou, S.-J.; Xu, D.-Q. Pd-Catalyzed para-Selective C-H Difluoromethylation of Aromatic Carbonyls. Chem. Commun. 2019, 55, 2019-2022; (j) Ruffoni, A.; Juliá, F.; Svejstrup, T. D.; McMillan, A. J.; Douglas, J. J.; Leonori, D. Practical and Regioselective Amination of Arenes Using Alkyl Amines. Nat. Chem. 2019, 11, 426-433.

(8) When this article was in preparation, Ritter and coworkers reported a related site-selective thianthrenation of arenes though thianthrene radical cation process. See: Berger, F.; Plutschack, M. B.; Riegger, J.; Yu, W.; Speicher, S.; Ho, M.; Frank, N.; Ritter, T. SiteSelective and Versatile Aromatic $\mathrm{C}-\mathrm{H}$ Functionalization by Thianthrenation. Nature, 2019, 567, 223-228.

(9) (a) Bur, S. K.; Padwa, A. The Pummerer Reaction: Methodology and Strategy for the Synthesis of Heterocyclic Compounds. Chem. Rev. 2004, 104, 2401-2432; (b) Feldman, K. S. Modern Pummerer-Type Reactions. Tetrahedron 2006, 62, 5003-5034. (c) Akai, S.; Kita, Y. Recent Advances in Pummerer Reactions. Top. Curr. Chem. 2007, 274, 35-76; (d) Smith, L. H. S.; Coote, S. C.; Sneddon, H. F.; Procter, D. J. Beyond the Pummerer Reaction: Recent Developments in Thionium Ion Chemistry. Angew. Chem. Int. Ed. 2010, 49, 5832-5844.

(10) (a) Lucken, E. A. C. 1,4-Dithiinium Radical-Cations. J. Chem. Soc. 1962, 4963-4965; (b) Müller, R.; Lamberts, L.; Evers, M. The Electrochemical Oxidation of Thioselenanthrene in Acetonitrile at Conventional Electrodes and Microelectrodes. J. Electroanal. Chem. 1996, 417, 35-43; (c) De Sorgo, M; Wasserman, B.; Szwarc, M. Aggregation of Salts of Thianthrene Radical Cations. J. Phys. Chem. 1972, 76, 3468-3471; (d) Glass, R. S.; Britt, W. J.; Miller, W. N.; Wilson, G. S. 2,3,7,8-Tetramethoxythianthrene Dication. Isolable Thianthrene Dication. J. Am. Chem. Soc. 1973, 95, 2375-2376; (e) Bock, H.; Rauschenbach, A.; Näther, C.; Kleine, M.; Havlas, Z. Thianthren-Radikalkation-Tetrachloroaluminat. Chem. Ber. 1994, 127, 2043-2049; (f) Nishinaga, T.; Wakamiya, A.; Komatsu, K. The First Isolation of the Hexafluoroantimonate Salt of a 1,4-Dithiin Radical Cation Stabilized by Bicyclo[2.2.2] octene Annelation. Tetrahedron Lett. 1999, 40, 43754378; (g) Rapta, P.; Kress, L.; Hapiot, P.; Dunsch, L. Dimerization of Thianthrene Radical Cations as Studied by in situ ESR and UV-VisNIR Voltammetry at Different Temperatures. Phys. Chem. Chem. Phys 2002, 4, 4181-4185.

(11) (a) Shine, H. J.; Silber, J. J. Ion radicals. XXII. Reaction of Thianthrenium Perchlorate $\left(\mathrm{C}_{12} \mathrm{H}_{8} \mathrm{~S}_{2} \cdot{ }^{+} \mathrm{ClO}^{4-}\right)$ with Aromatics. J. Org. Chem. 1971, 36, 2923-2926; (b) Kim, K.; Hull, V. J.; Shine, H. J. Ion Radicals. XXIX. Reaction of Thianthrene Cation Radical Perchlorate with Some Benzene Derivatives. J. Org. Chem. 1974, 39, 2534-2537; (c) Shin, S.-R.; Shine, H. J. Reactions of Phenols with Thianthrene Cation Radical. J. Org. Chem. 1992, 57, 2706-2710.

(12) (a) Hall, D. Boronic Acid: Preparation and Applications in Organic Synthesis and Medicine; Hall, D., Ed.; Wiley: Weinheim, Germany, 2005; (b) Suzuki, A.; Brown, H. C. Organic Synthesis via Boranes; Aldrich: Milwaukee, WI, 2003; Vol. 3. (c) Miyaura, N.; Suzuki, A. Palladium-Catalyzed Cross-Coupling Reactions of Organoboron Compounds. Chem. Rev. 1995, 95, 2457-2483. 
(13) For reviews, see: (a) Nenaidenko, V. G.; Balenkova, E. S. New Synthetic Capabilities of Sulfonium Salts. Russ. J. Org. Chem. 2003, 39, 291-330; (b) Tian, Z.-Y.; Hu, Y.-T.; Teng, H.-B.; Zhang, C.-P. Application of Arylsulfonium Salts as Arylation Reagents. Tetrahedron Lett. 2018, 59, 299-309. For selected examples, see: (c) Srogl, J.; Allred, G. D.; Liebeskind, L. S. Sulfonium Salts. Participants par Excellence in Metal-Catalyzed Carbon-Carbon Bond-Forming Reactions. J. Am. Chem. Soc. 1997, 119, 12376-12377; (d) Zhang, S.; Marshall, D.; Liebeskind, L. S. Efficient Pd-Catalyzed Heterobenzylic CrossCoupling Using Sulfonium Salts as Substrates and $(\mathrm{PhO})_{3} \mathrm{P}$ as a Supporting Ligand. J. Org. Chem. 1999, 64, 2796-2804; (e) Cowper, P.; Jin, Y.; Turton, M. D.; Kociok-Köhn, G.; Lewis, S. E. Azulenesulfonium Salts: Accessible, Stable, and Versatile Reagents for Cross-
Coupling. Angew. Chem., Int. Ed. 2016, 55, 2564-2568. (f) Wang, S.M.; Wang, X.-Y.; Qin, H.-L.; Zhang, C.-P. Palladium-Catalyzed Arylation of Arylboronic Acids with Yagupolskii-Umemoto Reagents. Chem. Eur. J. 2016, 22, 6542-6546; (g) Minami, H.; Otsuka, S.; Nogi, K.; Yorimitsu, H. Palladium-Catalyzed Borylation of Aryl Sulfoniums with Diborons. ACS Catal. 2018, 8, 579-583; (h) Aukland, M. H.; Talbot, F. J. T.; Fernández-Salas, J. A.; Ball, M.; Pulis, A. P.; Procter, D. J. An Interrupted Pummerer/Nickel-Catalysed Cross-Coupling Sequence. Angew. Chem., Int. Ed. 2018, 57, 9785-9789. 


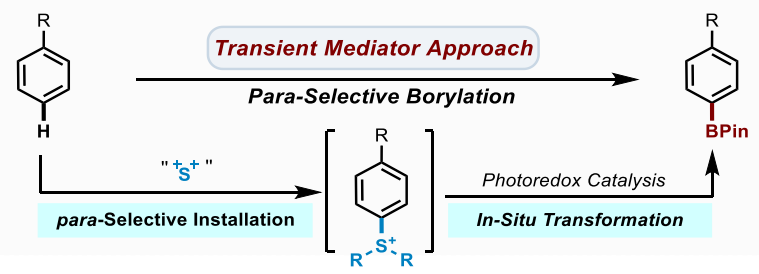

